\title{
Detection of the Stator Winding Inter-Turn Faults in Induction and Synchronous Machines through the Correlation Between Harmonics of the Voltage of Two Magnetic Flux Sensors
}

\author{
Miftah Irhoumah, Remus Pusca, Eric Lefevre, David Mercier, Raphael Romary
}

\begin{abstract}
This paper presents a statistical methodology for detection of inter-turn short circuit fault in asynchronous and synchronous machines. This methodology uses a correlation coefficient obtained from external magnetic field measured in the machine vicinity. It is a noninvasive method which follows up the signals of two external flux sensors located symmetrically around the machine axis $\left(\mathbf{1 8 0}^{\circ}\right.$ spatially shifted $)$. The principle is based on the calculation of the Pearson correlation coefficient between two signals delivered by two sensors S1 and S2 when the machine operates at different load conditions, which allows us to detect incipient faults in electrical induction and synchronous machines with a high probability of detection. Experimental tests are realized using two specific rewound machines to create inter-turn short circuit faults with different severity levels.
\end{abstract}

Keywords-Correlation Coefficient, Electricals Machines, InterTurn Fault, Fault Diagnosis, Magnetic Flux Sensors

\section{INTRODUCTION}

$\mathbf{I}_{\mathrm{N}}$ numerous previous works, it is shown that electrical machines incur a wide range of mechanical problems common to most machinery, like unbalance, bearing faults, resonance [1]-[5]. But electrical machines also incur their own specific set of problems, which are the result of mechanical, thermal, or electrical stress. In this case, monitoring devices relying the information provided by the magnetic fluxes produced by any incipient magnetic or electric unbalance may be efficiently used in addition to, or as alternatives to the widely used current monitoring. Based on numerous evaluation test, the stator current and external leakage flux were selected as the most practical signals containing the needed information for detection of the inter-turn short circuit faults [6]-[8]. In practice, there are many factors which can cause the stator winding faults as the supply voltage transient generated by

M. Irhoumah, R. Pusca, R. Romary members of Laboratory of Electrotechnical and Environmental Systems (LSEE) specializes in electrical engineering, University Artois, EA 4025 LSEE, F-62400, Bethune, France, (e-mail: miftah aldwiab_irhoumah@ens.univartois.fr;remus.pusca@univ-artois.fr; raphael.romary@univ-artois.fr ).

E. Lefevre, D. Mercier members of Laboratory of Computer Engineering and Automation (LGI2A) France specializes in Decision support for sustainable logistics and mobility, University Artois, EA 3926 LGI2A, F-62400, Bethune, France, (e-mail: david.mercier@univartois.fr; eric.lefevre@ univ-artois.fr). lightning, opening or closing of circuit breakers and also by variable frequency drives. Thermal and environmental stresses are another factor created by the overloading or by a hostile environment [9]. It is very useful to detect these faults at an early stage for safety operations of these machines, because the failures can lead to more energy consumption and unexpected stop of the system.

The history of fault detection and diagnosis of electrical motors goes back to almost the date of their invention but, over the last few years, there has been an increase in the application of many methods of diagnosis. Contemporary researchers have also been involved in rigorous researches to come up with more efficient and sensitive inter-turn winding faults detection schemes [10]-[12]. Recently, several methods used for the diagnosis of electrical machines, based on current signature analysis and vibration [13]-[15] have been developed. Although their effectiveness has been demonstrated, the generalization of these methods in the industrial environment remains limited because their cost is relatively important. A number of time frequency domain techniques have been also proposed, which includes Short Time Fourier Transform [16], Artificial Neural Networks [17], [18] and Improved Artificial Ant Clustering Technique [19]. Another technique used for induction motor fault detection exploits Artificial Intelligence tools, such as Expert Systems, Fuzzy Logic [20]. These techniques can detect faults in electrical machines, but their implementation requires complex data acquisition equipment, sometime additional measurements and takes a relatively long time [21].

In industrial applications, it is interesting to use fully noninvasive measurement methods to detect faults in electrical machines without stopping or modifying the operation systems as the method presented in [22], where the diagnosis is based on the analysis of sensitive harmonics when the reactive power varies. The advantage of this method is that it uses only the external magnetic field analysis, it is fully noninvasive, and it can be implemented for asynchronous (AM) and synchronous machines (SM).

The principle exposed in [22] considering a $11 \mathrm{~kW}$ AM is extended in this paper by introducing the calculation and the analysis of the Pearson correlation coefficient between two signals delivered by two coil sensors S1 and S2 with a 10kW 
SM. These sensors are located symmetrically relatively to the axis of the machine [23] and a specific harmonic of the electromotive forces induced in the coils is used as fault indicator to calculate the Pearson correlation coefficient. The interest of this extended study is double, firstly it allows the validation of the principle for a SM in order to generalize it and the second is that the considered machine allows us to realize the incipient faults (1,3 or 5 short-circuited turns) in order to test the reliability of the proposed method.

Compared to works [7], [24] which exploit the difference of variation and ratio of the amplitude of two coil sensors by fusion process of flux sensors signals using belief functions theory, this paper proposes the use of the Pearson correlation coefficient to summarize both information.

This paper is organized as follows: section II presents the methodology of the diagnosis procedure and the principle of the Pearson correlation coefficient and section III presents the experimental results demonstrating the validity of the proposed method.

\section{TECHNIQUE OF THE CORRELATION COEFFICIENT FOR FAULT DIAGNOSIS}

The principle of the method is schematized in Fig.1: two sensors $\boldsymbol{S} \boldsymbol{1}$ and $\boldsymbol{S} 2$ are placed at $180^{\circ}$ from each other around a machine. Those sensors measure the external magnetic field in the vicinity of the machine which may present internal faults.

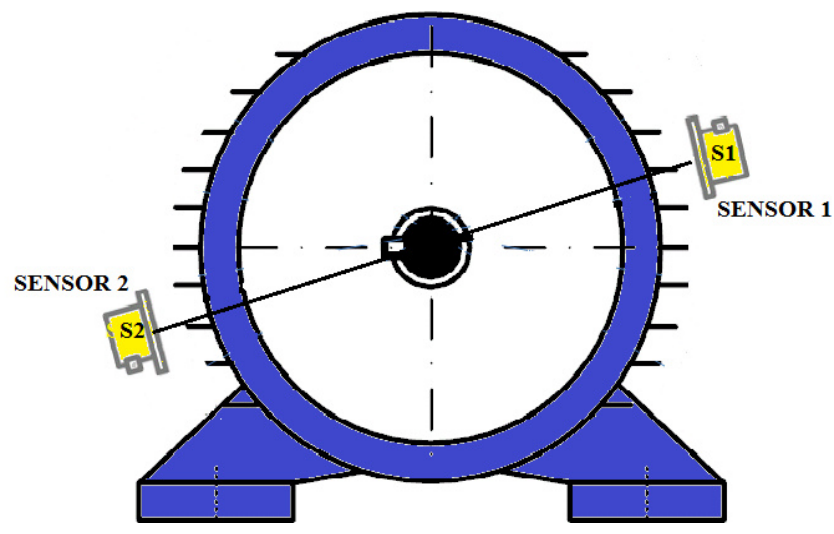

Fig. 1. Position 1 of sensors $\mathrm{S} 1$ and $\mathrm{S} 2$ placed at $180^{\circ}$ around the electrical machine.

The method exploits the magnetic dissymmetry induced by an internal stator winding inter-turn fault. In healthy case, the distribution of the field lines stays practically symmetrical around the machine. So, the signals measured by the sensors $\mathbf{S 1}$ and $\mathbf{S 2}$ are almost identically. In faulty case when a fault appears, the distribution of the magnetic field around the machine changes and its symmetry is lost as consequence of the new stator current distribution.

Due to the dissymmetry, the sensors $\boldsymbol{S} \boldsymbol{1}$ and $\boldsymbol{S} 2$ placed at $180^{\circ}$ from each other will provide signals with different magnitude. This phenomenon can be measured for machines with 4,6 , 8 ... poles, (only the 2 pole machine requires further analysis because the faulty machine remains symmetrical). In order to increase the sensitivity of the method, the analysis will not focus on the full signal but on a specific spectral line of the spectrum, which is known to be sensitive to a fault. In the following, the magnitude of this spectral line for the positions $\boldsymbol{S} \mathbf{1}$ and $\boldsymbol{S} \mathbf{2}$ will be denoted respectively $\boldsymbol{A S 1}$ and $\boldsymbol{A S 2}$.

For a stator inter-turn short circuit fault, these sensitive harmonics can be determined from an analytical model of the faulty machine that considers the slotting effect [8]. This model can be applied independently to asynchronous or asynchronous machines, by adapting the number of rotor and stator slots. It is shown that the corresponding frequency depends on the number of rotor slot $\mathrm{N}^{\mathrm{r}}$, the machine speed $\mathrm{n}$ [rpm] and the p pairs of pols. For a $50 \mathrm{~Hz}$ supply frequency, this sensitive frequency is given by:

$$
f_{s}=\frac{N^{r} n_{r} p}{60} \pm 50
$$

Equation (1) leads to define two frequencies. The method can be applied for both frequencies, but one is enough, the highest magnitude for example. The principle of the method, detailed in [24], is not to exploit $\boldsymbol{A S \boldsymbol { 1 }}$ and $\boldsymbol{A} \boldsymbol{S} \boldsymbol{2}$ as single data, but to analyze the variation of these magnitudes when the load of the machine changes. It is shown in [24], that feature can be extracted from these variations and therefore a diagnostic procedure can be defined. In this work, the proposed procedure uses the calculation of Pearson correlation coefficient $r$ between those specific harmonics in healthy and faulty conditions of the machine.

The population Pearson correlation coefficient, $\rho_{X, Y}$ between two random variables $X$ and $Y$ is defined as:

$$
\rho_{X, Y}=\frac{\operatorname{cov}(X, Y)}{\sigma_{X} \sigma_{Y}}
$$

where cov means covariance of $X$ and $Y$ and $\sigma_{X}$ and $\sigma_{Y}$ correspond respectively to the standard deviations of $X$ and $Y$

In case of a series of $n$ measurements of $X$ and $Y$ written as $\left\{x_{i} \mid 1 \leq i \leq n\right\}$ and $\left\{y_{i} \mid 1 \leq i \leq n\right\}$, then the Pearson correlation coefficient, noted $r$, is written as:

$$
r=\frac{\sum_{i=1}^{n}\left(x_{i}-\bar{x}\right)\left(y_{i}-\bar{y}\right)}{\sqrt{\sum_{i=1}^{n}\left(x_{i}-\bar{x}\right)^{2} \sum_{i=1}^{n}\left(y_{i}-\bar{y}\right)^{2}}}
$$

where $\bar{x}$ and $\bar{y}$ are the sample means of $X$ and $Y$

The correlation coefficient $r$ always belongs to the interval $[-1,1]$ [26], [27]. The values of $r$ can vary depending on the type of data, which are examined.

Let consider $\boldsymbol{A} \boldsymbol{s} \boldsymbol{1}$ and $\boldsymbol{A} \boldsymbol{s} \boldsymbol{2}$ the amplitudes of these variables in both positions, which are used as inputs to calculate the Pearson coefficient. Different values of $\boldsymbol{A s} \boldsymbol{1}$ and $\boldsymbol{A s} \boldsymbol{2}$ corresponding to various load conditions are considered. Considering a load increase, the method can be described as follows:

- If the values of $r$ are close to 1, there is a strong positive and linear correlation between $\boldsymbol{A s} \boldsymbol{1}$ and $\boldsymbol{A s} \mathbf{2}$, this means that variables vary similarly as shown in Fig. 2 . This indicates no fault in the stator windings of the machine. 


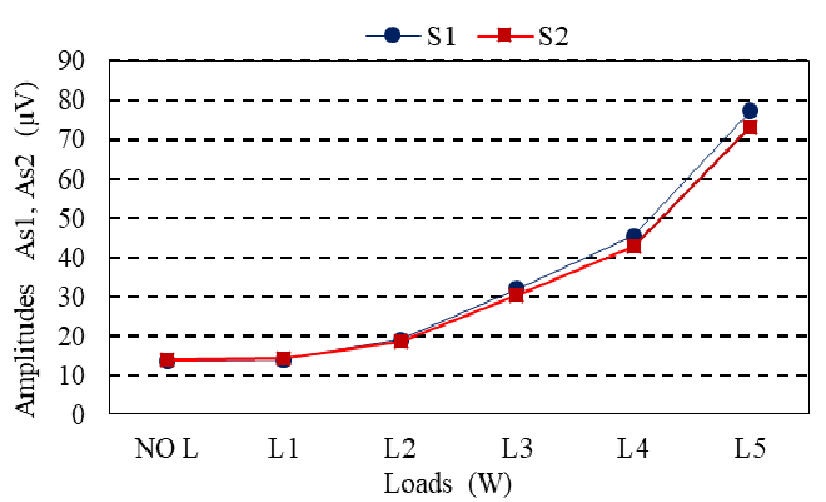

Fig. 2. Relationship between signals $A s_{1}$ and $A s_{2}$ for healthy condition of the machine and load variation when $r$ is close to 1 .

- If the value of $r$ is close to 0 , there is no linear correlation or a weak linear correlation between $\boldsymbol{A s} \boldsymbol{1}$ and $\boldsymbol{A s} \boldsymbol{2}$. This means that the variables do not change similarly, and it indicates a fault in the stator windings of the machine as shown in Fig.3.

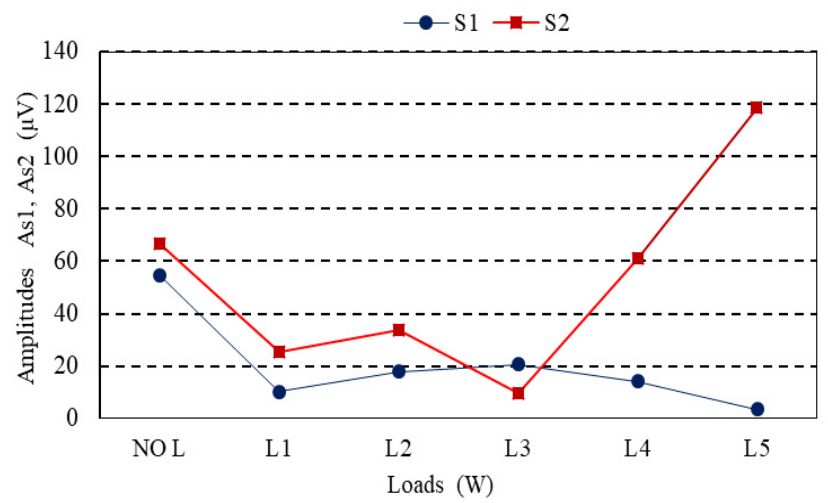

Fig. 3. Relationship between signals As 1 and As2 for faulty condition of the machine and load variation when $r$ is close to 0 .

- If the value of $r$ is close to -1 , there is a strong negative linear correlation between $\boldsymbol{A s} \mathbf{1}$ and $\boldsymbol{A s} \mathbf{2}$. This means that the variables vary in the opposite direction as shown in Fig.4. This also indicates a fault in the stator windings.

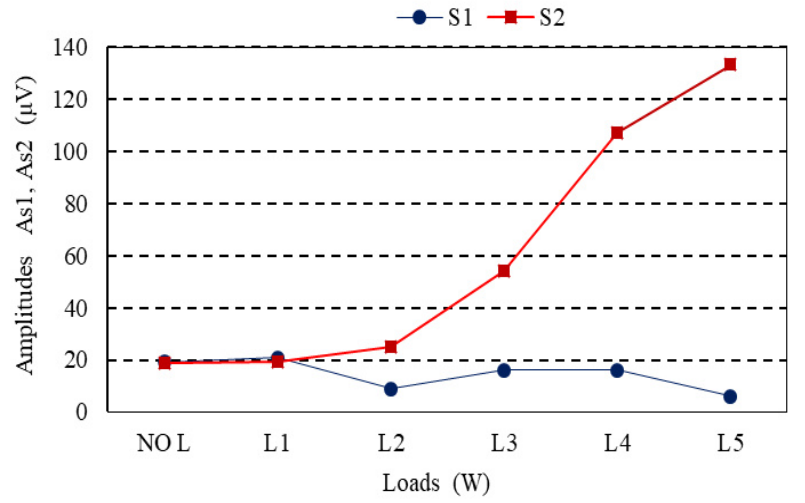

Fig. 4. Relationship between signals As 1 and As 2 for faulty condition of the machine and load variation when $r$ is close to -1 .

As with papers [7] and [24], this paper proposes to use the values of two flux sensors to detect stator winding inter-turn fault in electrical machines. Nonetheless, these approaches differ in the way to interpret these measures. In the papers [7] and [24], the same information, called difference of variation, is computed with these measurements. In [7], in addition of this information, the absolute value of the difference measurements is used to improve the detection. However, in order to use this last information, it is necessary to define a threshold which may differ from one machine to another. Another approach without threshold, called ratio of the amplitude, is proposed in [24]. This ratio has a natural tendency to overestimate the presence of defects. The approach being proposed here, based on Pearson correlation coefficient, is used to summarize both information difference variation and the difference measurements for [7] (or difference variation and ratio of the amplitude for [24]) without the weaknesses of the initial methods.

Moreover, in the papers [7] and [24], different positions of both sensors have been used to help the detection of defaults which cannot be detected in one position. Here only one position is used. This aspect could be study in future works.

\section{EXPERIMENTAL RESULTS}

\section{A. Description of the Experimental Test Bench}

This section presents experimental results obtained on two electrical machines which parameters are presented in Table I.

TABLE I

THE CHARACTERISTICS OF TESTED MACHINES

\begin{tabular}{|c|c|c|}
\hline & $\mathrm{AM}$ & $\overline{\mathrm{SM}}$ \\
\hline Machine type & asynchronous & synchronous \\
\hline Power (KW) & 11 & 10 \\
\hline Frequency $(\mathrm{Hz})$ & 50 & 50 \\
\hline Poles & 4 & 4 \\
\hline Stator slots & 48 & 54 \\
\hline Rotor slots & 32 & 32 \\
\hline Balanced line voltage (V) & $380 / 660$ & $220 / 400$ \\
\hline Synchronous speed (rpm) & 1500 & 1400 \\
\hline Rated speed (rpm) & 1450 & 1400 \\
\hline $\cos _{\varphi}$ & 0.83 & 0.7 \\
\hline
\end{tabular}

The asynchronous machine shown in Fig.5, with 32 rotor slots $\left(\mathrm{N}^{r}=32\right)$ leads to sensitive spectral lines at $750 \mathrm{~Hz}$ and $850 \mathrm{~Hz}$.

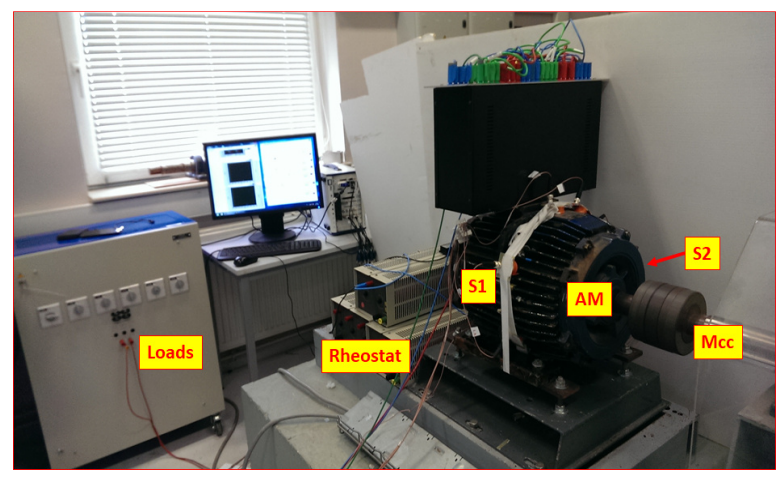

Fig. 5. Test bench for the $11 \mathrm{~kW}$ AM.

The line at $850 \mathrm{~Hz}$ is chosen for the analysis because 
experimental tests highlight a higher magnitude of the line at $850 \mathrm{~Hz}$ compared to the one at $750 \mathrm{~Hz}$. Actually, both harmonics have rather low magnitude, and for better robustness of the method it is preferable to take the one with higher magnitude. For the asynchronous machine, this frequency actually depends on the slip, but it will be still denoted as "the line at $850 \mathrm{~Hz}$ ".

The synchronous machine illustrated in Fig.6 is a machine with smooth rotor similar to the rotor of a turbo generator (contrarily to a salient pole machine). The rotor is regularly slotted similarly to the stator, with a DC current which flow through the winding. It has also 32 rotor slots $\left(\mathrm{N}^{r}=32\right)$ but some slots are not filled by the winding. Equation (1) also leads to sensitive spectral lines at $750 \mathrm{~Hz}$ and $850 \mathrm{~Hz}$, but for the synchronous machine, the $750 \mathrm{~Hz}$ spectral line has a higher magnitude than the $850 \mathrm{~Hz}$ one, contrarily to the asynchronous machine. Therefore, the $750 \mathrm{~Hz}$ line will be chosen for the analysis.

In a practical case, without any prior information about harmonic magnitudes, it can be advised to extract both harmonics from the signal, with an FFT. Then the one with the highest magnitude should be considered for the analysis with the Pearson coefficient. If the frequencies are rather similar, both can be considered and we recommend taking the result with the lowest correlation coefficient.

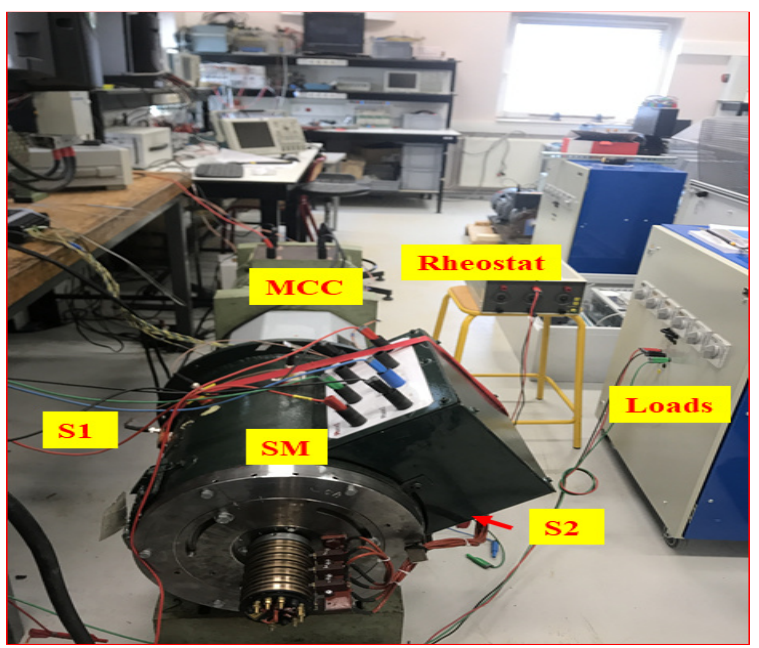

Fig. 6. Test bench for the $10 \mathrm{~kW} \mathrm{SM.}$

These two machines allow us to simulate a damaged coil (short-circuit coils) and to test the proposed method. For this purpose, a number of experiments are carried on in the considered machines. Each one is assembled and designed to study the behavior of the motor in faulty condition. So, for the tests, the stator winding of the machine has been modified to offer the possibility to make different levels of short circuits between turns as can be seen in electrical winding scheme presented in Fig. 7. This configuration allows us to shortcircuit any elementary coil (turns placed in one slot) in the stator windings that corresponds to $12.5 \%$ of a full phase. A rheostat is used to limit the value of short-circuit current during the tests.

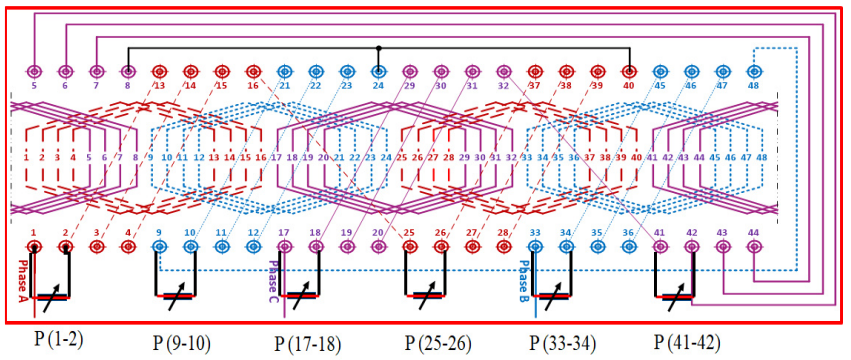

Fig. 7. Electrical winding scheme of asynchronous machine.

The measurements of the amplitudes $A \boldsymbol{s} \mathbf{1}$ and $A \boldsymbol{s} \mathbf{2}$ are achieved using 6 loads for AM and 6 loads for SM. As shown in Fig. 5 and Fig. 6 the two flux sensors $\boldsymbol{S} \boldsymbol{1}$ and $\boldsymbol{S} 2$ are placed in opposition (at $180^{\circ}$ ), against the machine in the middle to reduce the influence of end winding effects. Each sensor is a circular coil composed of 380 turns, which measures the external magnetic field around the machine and gives an emf proportional to it. The amplitude of this signal $(\mathrm{mV})$ is strongly depends on the machine frame attenuation, sensors position and number of turns, so the acquisition device must be able to measure with accuracy this type of signal. The signal spectrum is obtained considering the sampling frequency fixed at $\mathrm{f}_{\mathrm{e}}=10 \mathrm{Khz}$, acquisition time $\mathrm{T}_{\mathrm{a}}=10 \mathrm{~s}$ and a frequency resolution $\Delta f= \pm 0.1 \mathrm{~Hz}$. As for $A M$ and $S M$ the interest harmonics are inferior at $1 \mathrm{KHz}$, the signal is recorded by means of a numerical low pass filter with a limited frequency of $1500 \mathrm{~Hz}$. It has been proved that a simple external flux sensor is more efficient than the classical stator current signature analysis to detect inter turn short-circuit in threephase induction machine [23], [28].

\section{B. Calculation Example}

For AM, the amplitude variation of the harmonic at $850 \mathrm{~Hz}$ is analyzed considering a load increase. The six different load levels, corresponding to different output power chosen in the tests are: $\mathrm{L} 0=0 \mathrm{~W}, \mathrm{~L} 1=128 \mathrm{~W}, \mathrm{~L} 2=513 \mathrm{~W}, \mathrm{~L} 3=1260 \mathrm{~W}$, L4 $=2500 \mathrm{~W}$ and $\mathrm{L} 5=4000 \mathrm{~W}$.

TABLE II

MEASUREMENT OBTAINED FROM SENSORS S1 AND S2 AROUND THE HEALTHY AND FAULTY AM

$\begin{array}{lc}\text { HEALTHY } & \text { FAULTY } \\ \text { MACHINE } & \text { MACHINE }\end{array}$

\begin{tabular}{lllll}
\hline $\begin{array}{c}\text { LOADS } \\
(\mathrm{W})\end{array}$ & S1 $(\mu \mathrm{V})$ & $\mathrm{S} 2(\mu \mathrm{V})$ & $\mathrm{S} 1(\mu \mathrm{V})$ & $\mathrm{S} 2(\mu \mathrm{V})$ \\
\hline L0 & 13.58 & 13.98 & 55 & 67 \\
L1 & 13.94 & 14.13 & 10 & 26 \\
L2 & 18.9 & 18.53 & 18 & 34 \\
L3 & 32.02 & 30.41 & 21 & 10 \\
L4 & 45.33 & 42.73 & 14 & 61 \\
L5 & 77.27 & 72.89 & 4 & 119 \\
\hline \hline
\end{tabular}

To calculate the correlation coefficient $r$ with two variables $\boldsymbol{A s} \boldsymbol{1}$ and $\boldsymbol{A s} \mathbf{2}$, let us consider $\boldsymbol{x}$ the variable $\boldsymbol{A s} \boldsymbol{1}$ of sensor $\boldsymbol{S} \boldsymbol{1}, \boldsymbol{y}$ the variable $\boldsymbol{A} \boldsymbol{s} \boldsymbol{2}$ of sensor $\boldsymbol{S} \boldsymbol{2}$ and $\boldsymbol{n}_{\boldsymbol{l}}$ the number of loads. The 
measurements obtained by the sensors are summarized in Table II where the values obtained for a load increase, in healthy and faulty conditions for AM are reported.

From (3) and measurement presented in Table II, it comes results shown in Fig. 8.

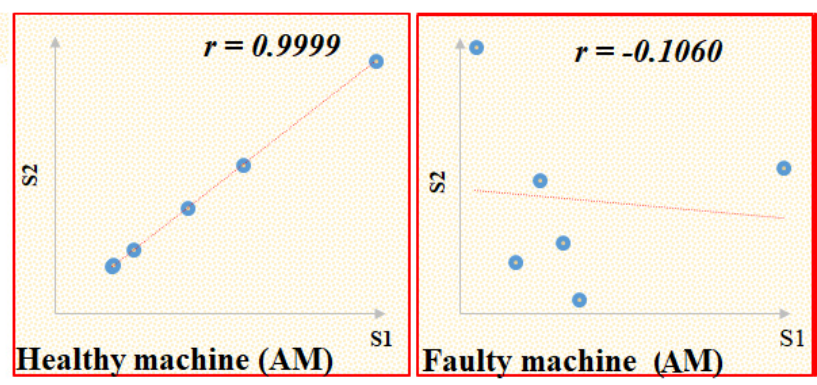

Fig. 8. Different values of the correlation coefficient $r$ for healthy and faulty asynchronous machine.

It can be seen that in healthy AM, there is a strong positive correlation coefficient ( $r=0.9999)$ between $\boldsymbol{A s} \boldsymbol{1}$ and $\boldsymbol{A s} \mathbf{2}$. This means that the variables vary in the same direction and there is a linear correlation between $\boldsymbol{A s} \boldsymbol{1}$ and $\boldsymbol{A s} \boldsymbol{2}$. In faulty conditions, it is calculated a very weak negative correlation coefficient $(r$ $=-0.1060$ ) between $\boldsymbol{A s} \boldsymbol{1}$ and $\boldsymbol{A s} \boldsymbol{2}$. It is obtained with 10A shortcircuit current in the circuit position at $\mathrm{P}$ (33-34) and its low value indicates a fault in the stator windings of the machine.

\section{Analysis Results for AM}

A series of measurements is realized for different positions of short circuit obtained in following cases:

- Without short-circuit.

- One fault on Phase A (short-circuits on coil 1-2).

- One fault on Phase B (short-circuits on coil 9-10).

- One fault on Phase C (short-circuits on coil 17-18).

- One fault on Phase A (short-circuits on coil 25-26).

- One fault on Phase B (short-circuits on coil 33-34).

- One fault on Phase C (short-circuits on coil 42-43).

For each case, measurements are performed with three values of the short circuit current: $\mathrm{I}_{\mathrm{cc}}=5 \mathrm{~A}, \mathrm{I}_{\mathrm{cc}}=10 \mathrm{~A}, \mathrm{I}_{\mathrm{cc}}=15 \mathrm{~A}$.

Table III gives the value of the correlation coefficient $r$ calculated with 6 load levels for different fault positions and different short circuit current values. So, 24 arrangements are analyzed: 6 healthy cases and 18 faulty cases.

TABLE III

CORRELATION COEFFICIENT VALUES OBTAINED FOR SENSORS S1 AND S2 PLACED IN OPPOSITION, $180^{\circ}$ AROUND OF AM.

\begin{tabular}{lllll}
\hline \hline $\begin{array}{c}\text { SHORT- } \\
\text { CIRCUIT }\end{array}$ & NOT FAULT & ICC $=5 A$ & ICc $=10 A$ & ICC $=15 A$ \\
\hline $\mathrm{P}(1-2)$ & 0.9999 & 0.9089 & 0.8562 & 0.6814 \\
$\mathrm{P}(9-10)$ & 0.9999 & 0.8686 & -0.4097 & 0.1971 \\
$\mathrm{P}(17-18)$ & 0.9999 & 0.9865 & 0.8644 & 0.8446 \\
$\mathrm{P}(25-26)$ & 0.9999 & 0.7550 & 0.9423 & 0.9427 \\
$\mathrm{P}(33-34)$ & 0.9999 & 0.6948 & -0.1060 & -0.1478 \\
$\mathrm{P}(42-43)$ & 0.9999 & -0.5642 & 0.5127 & 0.8677 \\
\hline \hline
\end{tabular}

In healthy condition of the machine, it can be observed that the correlation coefficient $r$ is very high and close to 1 $(r=0.9999)$. That represents the highest value obtained for all cases used for evaluation. In this case, the relationship between the two sensors is linear and indicates a strong positive correlation between the two variables.

In faulty condition, the magnetic dissymmetry generated by the fault leads to a difference between the signals delivered by sensors $\boldsymbol{S} \boldsymbol{1}$ and $\boldsymbol{S} 2$, and therefore between the magnitude $\boldsymbol{A s} \boldsymbol{I}$ and $A s \boldsymbol{2}$ of the $850 \mathrm{~Hz}$ sensitive harmonic. Then the correlation coefficient $r$ will fall down. This can be observed when in faulty condition $r$ decreases for all the cases relatively to the healthy cases.

Actually, the value of $r$ depends on the fault severity and the position of the short circuit in the machine relatively to the sensors locations. Let us analyze the influence of a threshold of $r$ value on the efficiency of the fault detection:

- For $r_{\max }=0.95$, the method can detect 17 faulty cases among the 18 existing ones. Here, the method can detect $94.4 \%$ of the faults.

- For $r_{\max }=0.90$, the method can detect $14 / 18$ faults. Here, even for a fault of high severity $\left(\mathrm{I}_{\mathbf{c c}}=15 \mathrm{~A}\right)$ one faulty case can be missed. Here, the method can detect $77.78 \%$ of the faults.

- For $r_{\max }=0.85$, the method can detect $50 \%$ of the faults for the $5 \mathrm{~A}$ short circuit case.

Figure 9 presents an illustration, from values in Table III of the correlation coefficient. Each corner represents the short circuit on specific coil (as example coil 1-2) which have the value $r=1$ for healthy machine.

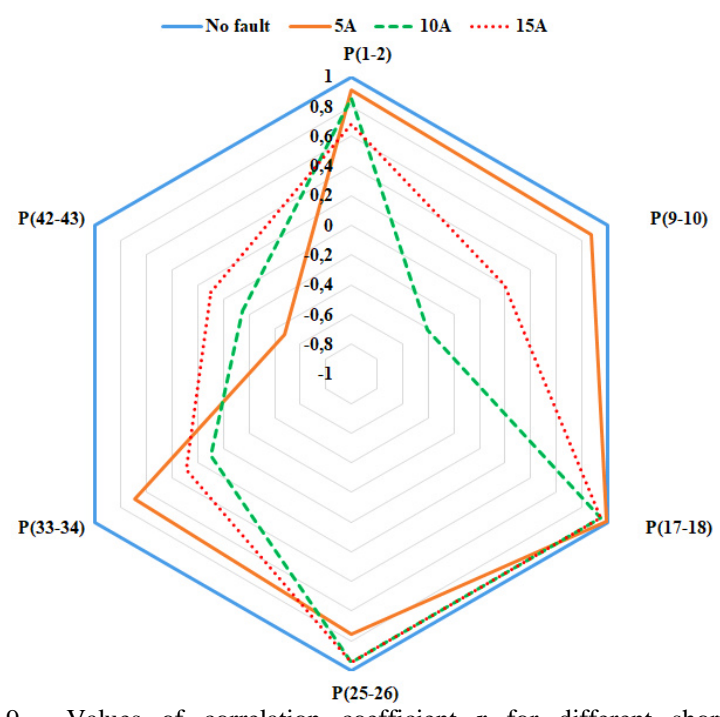

Fig. 9. Values of correlation coefficient $\boldsymbol{r}$ for different short-circuit currents and short circuit positions in the AM stator.

This presentation has the advantage of exposing simultaneously multiple faults and the distance of $r$ from 1 . We can remark a decrease of correlation coefficient $r$ for each short-circuit position, which generally decreases with the increase of the $I_{c c}$ current. For some positions, corresponding to a "good" positioning of the sensor related to short-circuit winding position this coefficient can turn into negative value. A low value for $r$ means that a fault is detected as is the case of $\mathrm{P}$ (42-43) with a short circuit current Icc=5A and when $r=-$ 0.5642 . 


\section{Analysis of the Results for SM}

In experimental tests for the synchronous machine operating as motor, the elementary sections have been chosen such that it is possible to study a short circuit close to the input of the phase (phase A), in phase medium (phase B) or near the neutral (Phase C) as presented in Fig.10. The global number of turns in the phase $\mathrm{A}$ is 126 and a short-circuit between 1-2 corresponds to one short-circuit turn ( $0.8 \%$ of a full phase), between $2-3$ to three short-circuit turns $(2.38 \%)$, and between $1-4$ to five short-circuit turns (4\%).

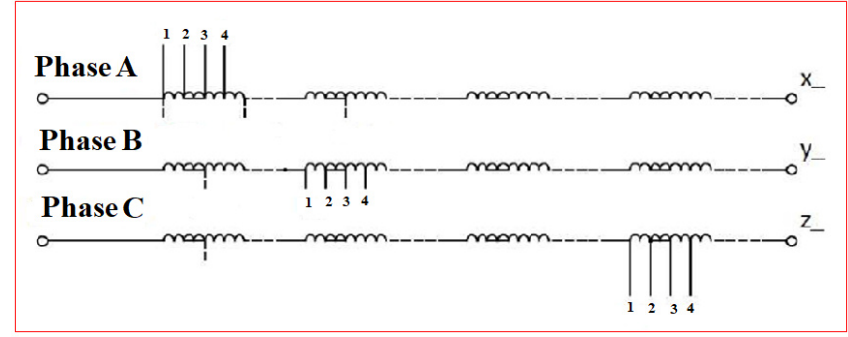

a)

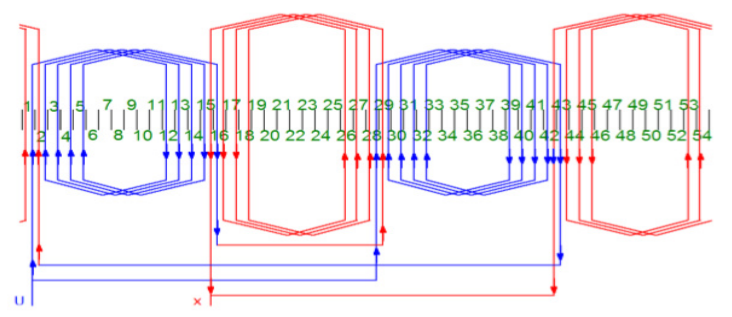

b)

Fig. 10. Stator configuration of synchronous machine: a) external access at different turns positions between the four pols of each phase b) electrical winding schema

As mentioned earlier, for this machine, the analyzed amplitude is realized for the harmonic at $750 \mathrm{~Hz}$. This choice is realized in correlation with (1) and with experimental tests which take in consideration the solid iron frame of the SM which acts as a low pass filter for magnetic field that leads to a higher magnitude for the $750 \mathrm{~Hz}$ harmonic compared to the one at $850 \mathrm{~Hz}$. The amplitude variation is analyzed considering a load increase. The six different output powers chosen for the tests are: $\mathrm{L} 0=0 \mathrm{~W}, \mathrm{~L} 1=830 \mathrm{~W}, \mathrm{~L} 2=2500 \mathrm{~W}, \mathrm{~L} 3=4900 \mathrm{~W}$, $\mathrm{L} 4=8020 \mathrm{~W}$ and $\mathrm{L} 5=9500 \mathrm{~W}$.

For the healthy synchronous machine, the correlation coefficient calculated between the magnitude $\boldsymbol{A s} \boldsymbol{1}$ and $\boldsymbol{A s} \boldsymbol{2}$ is very high and close to 1 ( $r=0.998$, Fig. 11$)$. It shown a linear correlation compared with the coefficient of the faulty SM ( $r=$ -0.5297) when a weak correlation between $A s \boldsymbol{1}$ and $\boldsymbol{A s} \mathbf{2}$ is obtained. This test is realized with a $3 \mathrm{~A}$ short circuit current and the short- circuit position at (1-2). This means that the variables do not change similarly, and it can indicate a fault in the stator windings of the machine.

To confirm the hypothesis that a low value of $r$ is an indicator of a fault presence in the machine, a series of measurements is realized for each load and for different positions of short circuit. They are realized as follows:

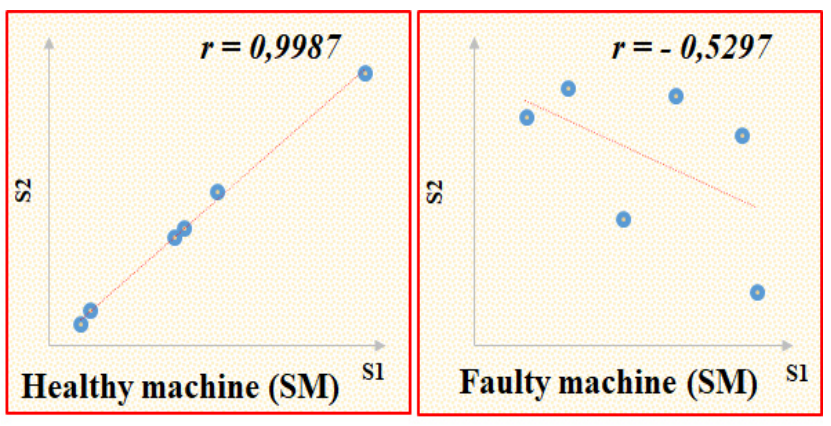

Fig. 11. Different values of the correlation coefficient $r$ for healthy and faulty SM.

- Without short-circuit,

- Three fault on Phase A (short-circuits between 1-2, 2-3, and 1-4),

- Three fault on Phase B (short-circuits between 1-2, 2-3, and 1-4),

- Three fault on Phase C (short-circuits between 1-2, 2-3, and 1-4).

The value of the measured current in each case of the short circuit fault was as follows:

$-I_{c c}=3 A$ for short-circuits on coil ' $1-2$ ', one shorted turn

$-I_{c c}=9 A$ for short-circuits on coil '2-3', three shorted turns

$-\mathrm{I}_{\mathrm{cc}}=15 \mathrm{~A}$ for short-circuits on coil ' 1 - 4', five shorted turns.

The results presented in Table IV will therefore be limited to the results obtained for motor operation.

TABLE IV

CORRELATION COEFFICIENT VALUES OBTAINED FOR SENSORS S1 AND S2 PLACED IN OPPOSITION, $180^{\circ}$ AROUND OF SM.

\begin{tabular}{ccccc}
\hline \hline SHORT- & NOT FAULT & $\mathrm{I}_{\mathrm{CC}}=3 \mathrm{~A}$ & $\mathrm{I}_{\mathrm{CC}}=9 \mathrm{~A}$ & $\mathrm{I}_{\mathrm{CC}}=15 \mathrm{~A}$ \\
CIRCUIT & & 1 TURN & 3 TURNS & 5 TURNS \\
\hline PHASE -A & 0.9987 & -0.5297 & 0.7469 & 0.9681 \\
PHASE -B & 0.9987 & 0.4935 & 0.8122 & 0.8078 \\
PHASE -C & 0.9987 & 0.5945 & 0.0173 & 0.4495 \\
\hline \hline
\end{tabular}

In Table IV the highest value of $r$ is obtained in healthy condition of the machine. In this case, the relationship between the two sensors is linear and indicates a strong positive correlation between the two variables.

The influence of the fault severity is tested by increasing the number of short-circuited turns at 1,3 or 5 , associated with an increase of the short-circuit current at 3A, 9A and $15 \mathrm{~A}$ (because here, the resistance that limits the short circuit current does not change). The aim of this test is to determine if an incipient fault can be detected and what is the sensitivity of the method. From Table IV it can be seen that the correlation coefficient always decreases compared to the healthy case.

Actually, the value of $r$ depends on the fault severity and the position of the short circuit in the machine relatively to the sensors locations. It is interesting to remark that, sometime a low incipient fault ( 1 turn) can give a fall down of the $r$ value (-0.5297) and a more important fault (5 turns) only a low variation (0.968). This was also the case for the AM (see Fig. 11, fault in $\mathrm{P}$ (42-43)). As for AM, a good fault detection depends on the chosen threshold level: 
- For $r_{\max }=0.97$, the method can detect 9 faulty cases among the 9 existing $9 / 9$.

- For $r_{\max }=0.90$, the method can detect $8 / 9$ faults.

- For $r_{\max }=0.85$, the method allows us to detect $8 / 9$ case as for the last threshold.

So, the method can detect $89 \%$ of the faults in most of the cases including also the case when the fault is only on one turn. A global analysis of the correlation coefficient value with simultaneous three phases is presented in Fig.12 where the great dissymmetry of the figure shown the fault detection for considered positions. The moving of the triangle corners towards the center of the blue triangle means a detection of the fault. We can remark a good sensitivity of this method for incipient faults (1 turn, $r=-0.5297$ ) and a decrease of the correlation coefficient for each faulty case. Here the level of the short circuit current is not essential for fault detection and the threshold value supports slight variations without notable changes in the percentage of fault detection.

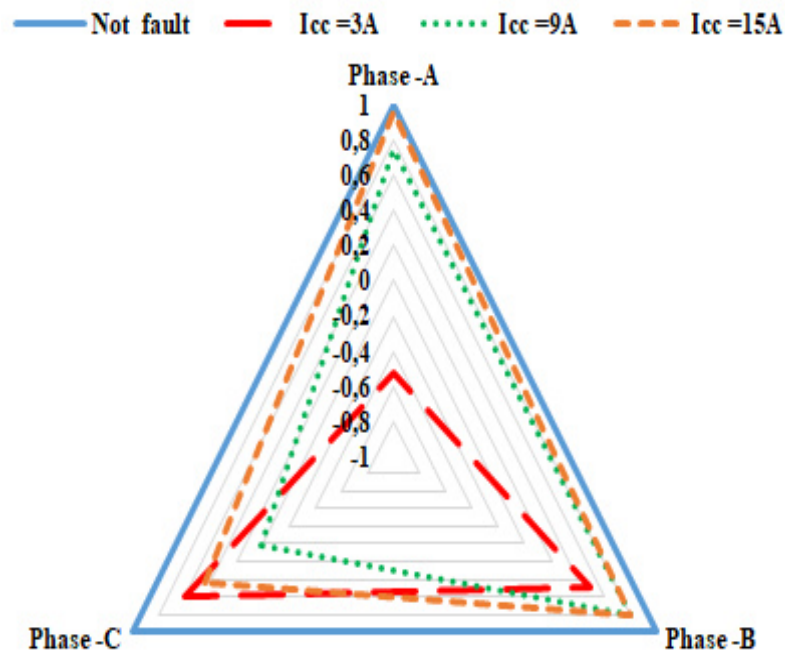

Fig. 12. Global presentation of correlation coefficient value considering the three phases of the SM and three short-circuit currents.

An increase of the fault detection percentage can be obtained with additional measurements at other sensor position, to increase to chance for the sensors to be close to the faulty winding axis. However, this requires more sensors, and need to have free space around the machine to place the sensors.

\section{CONCLUSION}

This paper presents a statistical methodology for detection of short-circuit faults in the stator windings for asynchronous and synchronous three phase machines. It proposes the calculation of a correlation coefficient $r$ obtained by analyzing the evolution of magnetic flux harmonics measured around of the machine frame in no load and load condition to detect the incipient faults. This diagnosis technique based on magnetic flux measurement is highly likely to meet criteria for this type of fault consequence of magnetic field sensitivity at low unbalanced created by faults.

The advantage of the proposed method is that it is reliable, inexpensive and simple to implement. This noninvasive method uses two flux coil sensors diametrically located to measure the external magnetic field in the vicinity of the machine. The method only needs the knowledge of the number of rotor slots. From this, frequencies of sensitive harmonics are deduced. Pearson correlation coefficient is proved a useful tool for detecting a fault by one indicator, its use in proposed application allow to detect $94 \%$ for (AMs) of the fault and $89 \%$ for (SMs) of the faults including when the fault is in one turn. Moreover, the method has a high-level accuracy and speed for the faults detections. On the other hand, this method does not require any knowledge on the presumed healthy state of the machine. A difference of values of the Pearson correlation coefficient is a good indicator of inter-turn short circuit fault and the increase of the fault detection percentage can be obtained with additional measurement at other sensor position if the sensors can been placed around the machine.

\section{References}

[1] V. Climente-Alarcon, D. Nair, R. Sundaria, J. A. Antonino-Daviu and A. Arkkio, "Combined model for simulating the effect of a heavy transient on a damaged rotor cage," 2016 XXII International Conference on Electrical Machines (ICEM), Lausanne, 2016, pp. 2867-2873.

[2] A. Petrov, I. Plokhov, A. Rassõlkin, T. Vaimann, A. Kallaste and A. Belahcen, "Adjusted electrical equivalent circuit model of induction motor with broken rotor bars and eccentricity faults," 2017 IEEE 11th International Symposium on Diagnostics for Electrical Machines, Power Electronics and Drives (SDEMPED), Tinos, 2017, pp. 58-64.

[3] E. Fournier, A. Picot, J. Régnier, M. T. Yamdeu, J. M. Andréjak and P. Maussion, "Current-Based Detection of Mechanical Unbalance in an Induction Machine Using Spectral Kurtosis With Reference," in IEEE Transactions on Industrial Electronics, vol. 62, no. 3, March 2015, pp. 1879-1887.

[4] M. Hamadache, D. Lee and K. C. Veluvolu, "Rotor Speed-Based Bearing Fault Diagnosis (RSB-BFD) Under Variable Speed and Constant Load," in IEEE Transactions on Industrial Electronics, vol. 62, no. 10 , Oct. 2015 , pp. 6486-6495.

[5] M. Kato and K. Hirata, "Proposal of electro mechanical resonance for linear oscillatory actuator," 2016 XXII International Conference on Electrical Machines (ICEM), Lausanne, 2016, pp. 871-876.

[6] M. Irhoumah, D. Mercier, R. Pusca, E. Lefèvre and R. Romary, "Information fusion of external flux sensors for detection of inter-turn short circuit faults in induction machines," IECON 2017 - 43rd Annual Conference of the IEEE Industrial Electronics Society, Beijing, 2017, pp. 8076-8081.

[7] R. Pusca, C. Demian, D. Mercier, E. Lefevre, R. Romary, “An improvement of diagnosis procedure for AC machines using two external flux sensors based on a fusion process with belief functions", 38th annual conference on IEEE Industrial Electronics Society, IECON2012, 25-28 October 2012, Montreal, Canada, pp. 5078-5083.

[8] R. Pusca, R. Romary and A. Ceban, "Detection of inter-turn short circuits in induction machines without knowledge of the healthy state," Electrical Machines (ICEM), 2012 XXth International Conference on, Marseille, 2012, pp. 1637-1642.

[9] T.Ch. Anil Kumar, V.N.A. "Naikan Induction motor inter turn fault detection using infrared thermographic analysis Infrared", ELSEVIER, vol. 77, July (2016), pp. 277-282.

[10] L. Frosini, S. Zanazzo and A. Albini, "A wavelet-based technique to detect stator faults in inverter-fed induction motors," 2016 XXII International Conference on Electrical Machines (ICEM), Lausanne, 2016, pp. 2917-2923.

[11] H. Henao, G. A. Capolino, M. F. Cabanas, F. Filippetti, C. Bruzzese, E. Strangas, R. Pusca, J. Estima, M. Riera-Guasp and S. H. Kia, "Trends in Fault Diagnosis for Electrical Machines: A Review, of Diagnostic Techniques," IEEE Industrial Electronics Magazine, vol. 8, no. 2, June 2014,pp. 31-42. 
[12] G. A. Capolino, J. A. Antonino-Daviu and M. Riera-Guasp, "Modern Diagnostics Techniques for Electrical Machines, Power Electronics, and Drives," in IEEE Transactions on Industrial Electronics, vol. 62, no. 3 , March 2015,pp. 1738-1745.

[13] C. Bianchini, F. Immovilli, M. Cocconcelli, R. Rubini and A. Bellini, "Fault Detection of Linear Bearings in Brushless AC Linear Motors by Vibration Analysis," in IEEE Transactions on Industrial Electronics, vol. 58, no. 5, May 2011, pp. 1684-1694.

[14] W. T. Thomson and M. Fenger, "Current signature analysis to detect induction motor faults," IEEE Ind. Appl. Mag., vol. 7, no. 4, Jul./Aug. 2001, pp. 26-34.

[15] A. Berzoy, A. A. S. Mohamed, Student Members, IEEE and O. A. Mohammed, Fellow, IEEE, "Stator Winding Inter-turn Fault in Induction Machines : Complex-Vector Transient and Steady-State Modelling", International Conference on Electrical Machines (ICEM) 2016, Lausanne, vol.22, pp. 2901-2907.

[16] A. Radecki, A. Dębowski, M. Wójcik and P. Lipnicki, "Evaluation of a diagnostic information on common electrical faults contained in signals of an inverter-fed AC IM drive with current-oriented control," 2016 10th International Conference on Compatibility, Power Electronics and Power Engineering (CPE-POWERENG), Bydgoszcz, 2016, pp. 286291.

[17] M. Barzegaran, A. Mazloomzadeh, O.A. Mohammed, "Fault diagnosis of the asynchronous machines through magnetic signature analysis using finite-element method and neural networks" IEEE Trans. On Energy Conversion, Vol. 28, October 201, pp. 1064-10713.

[18] S.S. Moosavi, A. Djerdir, Y. Ait-Amirat, D.A. Khaburi. "ANN based fault diagnosis of permanent magnet synchronous motor under stato winding shorted turn”, ELSEVIER, vol. 125, August (2015), pp. 67-82.

[19] A. Soualhi, G. Clerc and H. Razik, "Detection and Diagnosis of Faults in Induction Motor Using an Improved Artificial Ant Clustering Technique," in IEEE Transactions on Industrial Electronics, vol. 60, no. 9 , Sept. 2013, pp. 4053-4062.

[20] V. Delgado-Gomes, V. F. Pires, J. F. Martins, "A new teaching tool for fault detection in the induction machine" IEEE International Symposium on Industrial Electronics (ISIE), 23rd, 1-4 June 2014, pp. 2190 - 2195
[21] S. Kim, M. Ouyang and X. Zhang, "Compute spearman correlation coefficient with Matlab/CUDA," 2012 IEEE International Symposium on Signal Processing and Information Technology (ISSPIT), Ho Chi Minh City, 2012, pp. 000055-000060.

[22] M. Irhoumah, R. Pusca, E. Lefèvre, D. Mercier and R. Romary, "Diagnosis of induction machines using external magnetic field and correlation coefficient," 2017 IEEE 11th International Symposium on Diagnostics for Electrical Machines, Power Electronics and Drives (SDEMPED), Tinos, 2017, pp. 531-536.

[23] R. Pusca, R. Romary, A. Ceban, and J.-F. Brudny, "An Online Universal Diagnosis Procedure Using Two External Flux Sensors Applied to the AC Electrical Rotating Machines," Sensors,vol. 10, 2010, pp. 1044810466.

[24] M. Irhoumah, R. Pusca, E. Lefèvre, D. Mercier, R. Romary, C. Demian"Information Fusion With Belief Functions for Detection of Interturn Short-Circuit Faults in Electrical Machines Using External Flux Sensors", IEEE Transactions on Industrial Electronics, 2018, vol. 65 , no. 3, pp.2642-2652.

[25] K. Pearson, "Notes on Regression and Inheritance in the Case of Two Parents", in Proceedings of the Royal Society of London, vol. 58, Jan 1895 , pp. 240-242.

[26] A. M. Neto, A. C. Victorino, I. Fantoni and D. E. Zampieri, "Real-time dynamic power management based on Pearson's Correlation Coefficient," Advanced Robotics (ICAR), 2011 15th International Conference on, Tallinn, 2011, pp. 304-309.

[27] E. D. B. Solis, A. M. Neto and B. N. Huallpa, "Pearson's Correlation Coefficient for Discarding Redundant Information: Velodyne Lidar Data Analysis," 2015 12th Latin American Robotics Symposium and 2015 3rd Brazilian Symposium on Robotics (LARS-SBR), Uberlandia, 2015, pp. 116-119.

[28] H. Henao, C. Demian and G. A. Capolino, "A frequency-domain detection of stator winding faults in induction machines using an external flux sensor," in IEEE Transactions on Industry Applications, vol. 39, no. 5, Sept.-Oct. 2003, pp. 1272-1279. 